\title{
Surgical Outcomes of Phacoemulsification Surgery in a Restructured Asian Training Hospital
}

\author{
David Zhiwei Law, ${ }^{1,2}$ Seng Chee Loon, ${ }^{1}$ Wan Ling Wong, ${ }^{3,4}$ Marilou Sevilla Ebreo, ${ }^{1}$ \\ Xiang Li, ${ }^{4}$ Shantha Amrith ${ }^{1}$ \\ ${ }^{1}$ Department of Ophthalmology, National University Hospital, ${ }^{2}$ Singapore Armed Forces \\ Vision Performance Centre, Military Medicine Institute, ${ }^{3}$ Department of Ophthalmology, \\ Yong Loo Lin School of Medicine, National University of Singapore, and ${ }^{4}$ Singapore Eye \\ Research Institute, Singapore
}

\begin{abstract}
Aim: To evaluate the surgical outcomes of phacoemulsification performed at National University Hospital, Singapore, with emphasis on the results achieved by residents.

Methods: This was a retrospective analysis of surgical outcomes of patients who underwent phacoemulsification in a restructured hospital in 2008. The study included 318 eyes of patients of predominantly Asian descent. Pre-and postoperative best-corrected visual acuity, perioperative complications and associations of patient, surgical and surgeon factors were studied. One-way analysis of variance for means, chi-squared test for proportions, and multivariate analyses were performed to determine factors associated with postoperative best-corrected visual acuity outcomes. Main outcome measures included postoperative best-corrected visual acuity, degree of improvement in best-corrected visual acuity, and achievement of specific best-corrected visual acuity targets of $6 / 9$ and 6/12 at postoperative months 1 and 3 .

Results: Duration of surgery of less than 20 minutes was found to be significantly associated with better postoperative best-corrected visual acuity. Level of surgical experience was also associated with better postoperative best-corrected visual acuity at postoperative months $1(p<0.001)$ and $3(p=0.004)$. While senior consultants produced the best postoperative best-corrected visual acuity outcomes, the results achieved by residents were comparable to those reported in prior resident-only studies. For surgeries performed by residents, the overall rate of posterior capsule rupture was $3.1 \%$ with a $0.0 \%$ rate of vitreous loss.

Conclusions: The continued close guidance and training of ophthalmology residents in a restructured Asian training hospital will ensure that complication rates remain low while maintaining postoperative outcomes at safe levels.
\end{abstract}

Key words: Phacoemulsification, Posterior capsular rupture, ocular, Postoperative complications, Visual acuity

Asian J Ophthalmol. 2011;12:201-7.

\section{Introduction}

Phacoemulsification is the most common ophthalmic surgical procedure performed in Singapore. To ensure continued safe standards of care and improved postoperative outcomes at the National University Hospital (NUH), Singapore, retrospective analyses of key performance indicators such as postoperative best-corrected visual acuity (BCVA), degree of improvement in postoperative $\mathrm{BCVA}$, and postoperative complications are reviewed on a regular

Correspondence: Dr David Zhiwei Law, Department of Ophthalmology, National University Hospital, 5 Lower Kent Ridge Road, Singapore 119074.

Tel: (65) 9825 6630;

E-mail: joc_81@yahoo.co.uk basis and bench-marked against other standards of care..$^{1-11}$ These indicators reflect the surgeon's level of competence and are associated with the degree of guidance given to newly-inducted ophthalmology residents. This paper reports on the postoperative outcomes of phacoemulsification in a Singapore training hospital, with emphasis on the results obtained by residents.

\section{Methods \\ Patients}

This was a retrospective analysis of a predominantly Asian population. The case files of patients who underwent phacoemulsification in the first month of each quarter of 2008 (January, April, July, and October) were retrieved from the NUH Medical 
Records Office and reviewed. Patients with pre-existing ocular disease were excluded from the analysis, leaving 318 patients in the study group. Various data were collected relating to patient (age, sex, race), surgical (duration of surgery, type of anaesthesia side of eye undergoing operation) and surgeon (level of surgical experience) factors. The preoperative and postoperative BCVAs (at months 1 and 3) were recorded and the degree of improvement in BCVA at these postoperative milestones was calculated using LogMAR equivalent values. Patients who were lost to follow-up at each milestone were excluded from subsequent analysis. The types and rates of perioperative complications were also studied. All data collection was performed by a single independent staff member.

Ethics approval to conduct the study was obtained from the National Healthcare Group Institutional Review Board, Singapore, and the study conforms to the principles of the Declaration of Helsinki (1995).

\section{Statistical Analysis}

For the purposes of the study, BCVA was measured preoperatively and at months 1 and 3 , although all patients were routinely given follow-up appointments at postoperative day 1 , week 1 , and months 1 and 3 in accordance with the hospital's standard practice guidelines. All BCVA data were converted into LogMAR equivalent values to allow for calculation of degree of postoperative BCVA improvement (postoperative BCVA minus preoperative BCVA).

The collected data were analysed using the Statistical Package for the Social Sciences version 17.0 (SPSS Inc, Chicago, USA). Differences in means and proportions were tested by analysis of variance (ANOVA) and chi-squared test, respectively, for BCVA at postoperative month 1 and postoperative month 3. Multivariate analysis using logistic regression models was further used for assessing factors associated with achieving specific postoperative BCVA targets.

Table 1. Patients' demographics and baseline characteristics $(n=318)$.

\begin{tabular}{lc|}
\hline Characteristic & Number (\%) \\
\hline Mean age (range) [years] & $66.54(20-97)$ \\
Sex & \\
$\quad$ Male & $162(50.9)$ \\
Female & $156(49.1)$ \\
Race & \\
Chinese & $245(77.0)$ \\
Malay & $37(11.6)$ \\
Indian & $21(6.6)$ \\
Eurasian & $0(0)$ \\
Caucasian & $4(1.3)$ \\
Others & $11(3.5)$ \\
Side of surgery & \\
Right & $149(46.9)$ \\
Left & $169(53.1)$ \\
\hline
\end{tabular}

\section{Results \\ Patients}

318 eyes were included in the study. Excluding non-permanent residents and non-citizens, the racial distribution was a reasonable representation of the ethnic distribution of Singapore's total resident population (from the Singapore Department of Statistics Population Trend for $2008^{12}$ ) of Chinese (74.7\%), Malay (13.6\%), Indian (8.9\%), and other races $(2.8 \%)$. The patients' demographic details are shown in Table 1.

\section{Surgical Outcomes}

The mean duration of surgery was 29.1 minutes (range, 10-75 minutes). This duration followed a Gaussian distribution with a median time of 25.0 minutes (SD, 10.8 minutes).

With regard to type of anaesthesia, 275 eyes (86.5\%) were operated under topical anaesthesia, $39(12.3 \%)$ under regional anaesthesia (peribulbar or retrobulbar), and $4(1.3 \%)$ under general anaesthesia.

112 surgeries (35.2\%) were performed by senior consultants, $128(40.3 \%)$ by consultants, 11 (3.5\%) by associate consultants, $2(0.6 \%)$ by clinical fellows, $41(12.9 \%)$ by registrars (Advanced Specialty Training trainees equivalent to fourth- to sixth-year residents and competent in performing extracapsular cataract extraction [ECCE] independently), and 24 (7.6\%) by medical officers (Basic Specialty Training [BST] trainees equivalent to at least third-year residents who have performed $\geq 50$ supervised ECCEs).

\section{Visual Acuity}

The associations of various patient, surgical, and surgeon factors with postoperative BCVA at postoperative months 1 and 3 are shown in Table 2. Better postoperative BCVAs were achieved for men than for women at month $1(p=0.012)$ and month 3 $(p=0.002)$. At month 1 , better postoperative BCVAs were noted in patients younger than 50 years $(p<0.001)$ than in older patients. At month 3, better postoperative BCVAs were associated with patients aged 50 to 69 years than with patients aged 70 years or older $(p=0.003)$.

Duration of surgery of less than 20 minutes was associated with better postoperative BCVA at month $1(p<0.001)$ and month $3(p=0.001)$ than longer surgeries. The use of topical anaesthesia was associated with better postoperative BCVA than regional or general anaesthesia at month $3(p=0.004)$.

The level of surgical experience was a statistically significant factor associated with postoperative BCVA at month $1(p<0.001)$ and month $3(p=0.004)$. Although senior consultants produced the best postoperative BCVA, medical officers operating under 
Table 2. Patient, surgical, and surgeon factors associated with best-corrected visual acuity at postoperative months 1 and $3(n=318)$.

\begin{tabular}{|c|c|c|c|c|c|}
\hline Factor & $\begin{array}{l}\text { Number of } \\
\text { patients }\end{array}$ & $\begin{array}{c}\text { Month } 1 \\
\text { LogMAR (SD) }\end{array}$ & p Value ${ }^{\dagger}$ & $\begin{array}{c}\text { Month } 3 \\
\text { LogMAR (SD) }\end{array}$ & p Value ${ }^{\dagger}$ \\
\hline Sex & & & 0.012 & & 0.002 \\
\hline Male & 162 & $0.084(0.100)$ & & $0.050(0.075)$ & \\
\hline Female & 156 & $0.113(0.101)$ & & $0.085(0.091)$ & \\
\hline Race & & & 0.985 & & 0.637 \\
\hline Chinese & 245 & $0.098(0.102)$ & & $0.066(0.085)$ & \\
\hline Malay & 37 & $0.100(0.102)$ & & $0.063(0.083)$ & \\
\hline Indian & 21 & $0.094(0.090)$ & & $0.067(0.081)$ & \\
\hline Other (includes Eurasian, Caucasian) & 15 & $0.106(0.121)$ & & $0.096(0.101)$ & \\
\hline Age (years) & & & $<0.001$ & & 0.003 \\
\hline$<50$ & 14 & $0.057(0.096)$ & & $0.076(0.106)$ & \\
\hline $50-69$ & 182 & $0.080(0.094)$ & & $0.052(0.077)$ & \\
\hline$\geq 70$ & 122 & $0.131(0.105)$ & & $0.089(0.090)$ & \\
\hline Duration of surgery (minutes) & & & $<0.001$ & & 0.001 \\
\hline$<20$ & 32 & $0.058(0.096)$ & & $0.030(0.054)$ & \\
\hline $20-29$ & 137 & $0.082(0.087)$ & & $0.062(0.079)$ & \\
\hline $30-39$ & 84 & $0.110(0.101)$ & & $0.063(0.085)$ & \\
\hline$\geq 40$ & 65 & $0.141(0.118)$ & & $0.104(0.100)$ & \\
\hline Type of anaesthesia & & & 0.082 & & 0.004 \\
\hline Topical & 275 & $0.094(0.098)$ & & $0.061(0.081)$ & \\
\hline Regional (peribulbar or retrobulbar) & 39 & $0.130(0.116)$ & & $0.108(0.103)$ & \\
\hline General & 4 & $0.000(0.000)$ & & $0.000(0.000)$ & \\
\hline Level of surgical experience & & & $<0.001$ & & 0.004 \\
\hline Senior consultant & 112 & $0.071(0.090)$ & & $0.044(0.073)$ & \\
\hline Consultant & 128 & $0.126(0.103)$ & & $0.088(0.086)$ & \\
\hline Associate consultant & 11 & $0.079(0.100)$ & & $0.091(0.110)$ & \\
\hline Fellow & 2 & $0.180(0.000)$ & & $0.000(0.000)$ & \\
\hline Registrar (AST resident) & 41 & $0.111(0.114)$ & & $0.075(0.087)$ & \\
\hline Medical officer (BST resident) & 24 & $0.068(0.086)$ & & $0.048(0.092)$ & \\
\hline Perioperative complications & & & 0.058 & & 0.004 \\
\hline No & 258 & $0.093(0.098)$ & & $0.059(0.077)$ & \\
\hline Yes & 60 & $0.122(0.112)$ & & $0.096(0.107)$ & \\
\hline
\end{tabular}

${ }^{*}$ Only operated eyes of patients who completed follow-up at postoperative months 1 and 3 , were included in the analysis of postoperative best-corrected visual acuity. ${ }^{t} \mathrm{p}$ Value for the difference in patient, surgical, and surgeon factors at postoperative months 1 and 3 , based on 1-way analysis of variance or chi-squared test.

Abbreviations: AST = Advanced Specialty Training; BST = Basic Specialty Training.

the close supervision of attending consultants achieved clinically similar postoperative BCVAs at both postoperative milestones (Table 2).

The association of patient, surgical, and surgeon factors with the degree of postoperative improvement in BCVA at months 1 and 3 was not statistically significant.

Table 3 shows the factors associated with specific postoperative BCVA targets of $6 / 9$ or better and $6 / 12$ or better at months 3 and 1 , respectively. Multivariate analysis showed that women had a lower likelihood of achieving a postoperative BCVA of $6 / 9$ or better at month 3 (odds ratio [OR], 0.10; 95\% confidence interval [CI], $0.01-0.93 ; p=0.043)$. There was no association of sex with the likelihood of achieving a postoperative BCVA of either 6/9 or better at month 1 or $6 / 12$ or better at months 1 and 3 .

Multivariate analysis showed that age, race, duration of surgery, level of surgical experience, and type of anaesthesia were not associated with specific postoperative BCVA of $6 / 9$ or better and $6 / 12$ or better at months 1 and 3 .

\section{Complications}

ANOVA showed that absence of perioperative complications was associated with better postoperative BCVA at month 3 $(p=0.004)$ [Table 2]. Multivariate analysis showed that absence of perioperative complications was associated with a likelihood of achieving a postoperative BCVA of 6/12 or better at month 1 (OR, $0.11 ; 95 \% \mathrm{Cl}, 0.02-0.56 ; p=0.008$ ) and a BCVA of $6 / 9$ or better at month 3 (OR, 0.11; 95\% Cl, 0.02-0.46; $p=0.003$ ) [Table 3].

Perioperative complications ( $\geq 1$, mild to severe) were noted in 60 eyes $(18.9 \%)$. These included posterior capsule opacity in 20 eyes $(6.3 \%)$, posterior capsule rupture (PCR) in $11(3.5 \%)$, postoperative glaucoma in $6(1.9 \%)$, zonulysis in $4(1.3 \%)$, cystoid macular oedema in $2(0.6 \%)$, iris prolapse in $2(0.6 \%)$, iris trauma in $1(0.3 \%)$, and other complications of subconjunctival haemorrhage, corneal oedema, persistent inflammation, Descemet's membrane tears, epiretinal membrane, and intraocular lens-related complications in $21(6.6 \%)$. There were no patients with retinal detachment or endophthalmitis. Notably, the total PCR rate for 
Table 3. Association of sex and perioperative complications with postoperative best-corrected visual acuity of $6 / 9$ or better at month 3 and best-corrected visual acuity of $6 / 12$ or better at postoperative month $1(n=318)$.

\begin{tabular}{|c|c|c|c|}
\hline Factor & Number of patients* & Multivariate adjusted odds ratio ( $95 \%$ confidence interval) ${ }^{\dagger}$ & p Value \\
\hline \multicolumn{4}{|c|}{ BCVA $6 / 9$ or better at month 3} \\
\hline \multicolumn{4}{|l|}{ Sex } \\
\hline Male & 162 & 1.00 & \\
\hline Female & 156 & $0.10(0.01-0.93)$ & 0.043 \\
\hline \multicolumn{4}{|c|}{ Complications } \\
\hline No & 258 & 1.00 & \\
\hline Yes & 60 & $0.11(0.02-0.46)$ & 0.003 \\
\hline \multicolumn{4}{|c|}{ BCVA $6 / 12$ or better at month 1} \\
\hline \multicolumn{4}{|c|}{ Sex } \\
\hline Male & 162 & 1.00 & \\
\hline Female & 156 & $0.10(0.01-1.08)$ & 0.057 \\
\hline \multicolumn{4}{|c|}{ Complications } \\
\hline No & 258 & 1.00 & \\
\hline Yes & 60 & $0.11(0.02-0.56)$ & 0.008 \\
\hline
\end{tabular}

${ }^{*}$ Only operated eyes of patients who completed follow-up at postoperative months 1 and 3 , were included in the analysis of postoperative best-corrected visual acuity.

${ }^{\dagger}$ Adjusted for age, race, sex, duration of surgery, type of anaesthesia, level of surgical experience, and complications.

Table 4. Analysis of posterior capsule rupture with or without vitreous loss according to level of surgical experience.

\begin{tabular}{|lcccc|}
\hline Level of surgical experience & $\begin{array}{c}\text { Total number } \\
\text { of eyes }\end{array}$ & $\begin{array}{c}\text { Posterior capsule rupture } \\
\text { Number (\%) }\end{array}$ & $\begin{array}{c}\text { Posterior capsule rupture } \\
\text { without vitreous loss } \\
\text { Number (\%) }\end{array}$ & $\begin{array}{c}\text { Posterior capsule rupture } \\
\text { with vitreous loss } \\
\text { Number (\%) }\end{array}$ \\
\hline Senior consultant & 112 & $3(2.7)$ & $2(1.8)$ & $1(0.9)$ \\
Consultant & 128 & $6(4.7)$ & $2(1.6)$ & $4(3.1)$ \\
Associate consultant & 11 & $0(0)$ & $0(0)$ & $0(0)$ \\
Fellow & 2 & $0(0)$ & $0(0)$ & $0(0)$ \\
Registrar (AST resident) & 41 & $2(4.9)$ & $2(4.9)$ & $0(0)$ \\
Medical officer (BST resident) & 24 & $0(0)$ & $0(0)$ & $0(0)$ \\
All residents (registrars and medical officers) & 65 & $2(3.1)$ & $2(3.1)$ & $0(0)$ \\
All levels & 318 & $11(3.5)$ & $6(1.9)$ & $5(1.6)$ \\
\hline
\end{tabular}

Abbreviations: AST = Advanced Specialty Training; BST = Basic Specialty Training

residents was $3.1 \%$ when analysed according to level of surgical experience (Table 4).

\section{Discussion}

The results of this study show that race is not associated with postoperative BCVA outcomes at months 1 and 3. The likelihood of achieving a postoperative BCVA of $6 / 9$ or better at month 3 is associated with male sex. However, there is no clear clinical explanation for this observation, which may be a chance finding.

Compared with patients aged 50 years or older, operated eyes of patients younger than 50 years had better postoperative BCVA at month 1 while patients aged 50 to 69 years had better postoperative BCVA at month 3 than patients aged 70 years or older. These results may be explained by the increased prevalence of age-related changes such as age-related macular degeneration and chorioretinal atrophy, which were not clinically evident preoperatively due to the presence of cataracts.

Duration of surgery was significantly associated with postoperative BCVA at both month $1(p<0.001)$ and month $3(p=0.001)$, with better postoperative LogMAR values obtained for surgeries of less than 20 minutes. This result is likely to be a reflection of the level of surgical experience, whereby more experienced surgeons would be expected to take a shorter time to complete the operation. Of the 32 surgeries performed in less than 20 minutes, 28 (87.5\%) were performed by surgeons of consultant level and above. It is possible that operations of shorter duration performed by experienced surgeons are associated with reduced intraoperative manipulation of intraocular tissues, which results in a decrease in postoperative corneal oedema, inflammation, and other associated complications.

The use of local anaesthesia was associated with better postoperative BCVA at months 1 and 3 by 1 -way ANOVA than regional and general anaesthesia. There were no data on the preexisting systemic medical conditions of the patients, their physical or mental fitness for surgery, or type and degree of the cataracts (specifically the degree of nucleosclerosis) in this study, all of which may influence the choice of anaesthesia used. However, it is possible that the surgeon's preoperative assessment of the level of difficulty of surgery based on preoperative clinical ocular examination and overall assessment of patient fitness 
for surgery may have influenced the choice of anaesthesia. In these circumstances, it is possible that 'easier' eyes of younger and seemingly healthier patients with a lower likelihood of intraoperative ocular and systemic complications, shorter expected duration of surgery, and probable better postoperative BCVA may have been operated on using topical anaesthesia. In view of the multiple possible confounding factors, it is difficult to establish an independent association between the type of anaesthesia chosen and the observed postoperative BCVA.

The most significant finding in this study reinforces the fact that better surgical outcomes are associated with a surgeon's level of competence. In this study, the surgeon's level of experience was significantly associated with postoperative BCVA, with senior consultants producing the best postoperative BCVA at months 1 and 3. This result was statistically and clinically significant.

Phacoemulsification, like any other surgery, presents a steep and intimidating learning curve to the resident. Oetting showed that the resident learning curve increases the risk of complications in early operations, ${ }^{13}$ while surveys conducted by Binnbaum and Volpe of programme directors' experiences of training residents in cataract surgery showed that 1 in 10 residents encountered significant difficulties while learning cataract surgery. ${ }^{14}$ Other authors further demonstrated the presence of a clear resident learning curve in large US ophthalmology resident training programmes, noting that complication rates invariably decline with experience. ${ }^{15-19}$ Although seemingly obvious, the surgeon's level of surgical experience remains the most important factor determining favourable outcomes in phacoemulsification.

It is reassuring to note that the mean postoperative BCVA LogMAR values of patients undergoing phacoemulsification by medical officers under close consultant supervision are similar to those of senior surgeons. This observation was statistically significant and clinically relevant, although both groups cannot be effectively matched and compared due to differences in sample sizes. Nonetheless, this result strongly correlates with the close supervision given to ophthalmology residents by attending consultants in Singapore training hospitals. Additionally, surgical residents in Singapore are expected to complete $\geq 50$ ECCEs in the first 2 years of their BST programme prior to becoming eligible for commencement of training in phacoemulsification (usually in their third year of BST). This requirement would invariably equip the resident commencing phacoemulsification training with the necessary microsurgical skills and confidence to produce consistent postoperative results and deal with complications safely.

For comparison with other resident-only studies, the postoperative BCVAs achieved for eyes operated on only by residents were analysed. Of the 64 patients in this group who attended for follow-up at month 1, 63 (98.4\%) had a BCVA of 6/12 or better and $55(85.9 \%)$ had a BCVA of $6 / 9$ or better. At month 3 , of 55 patients still attending for follow-up, $55(100 \%)$ had a BCVA of $6 / 12$ or better while $52(94.5 \%)$ had a BCVA of $6 / 9$ or better. These results are comparable with those reported in other resident-only studies (Table 5). ${ }^{5-7}$

The types and rates of complications of phacoemulsification serve as a measure of the patient safety profile, an important consideration by patients, their families, and referring physicians. In this study, the total PCR rate was $3.5 \%$, with a rate of vitreous loss of $1.6 \%$ (including surgeons of all levels of surgical experience). When analysed according to the level of surgical experience, the combined PCR rate for residents was $3.1 \%$, with a $0 \%$ rate of vitreous loss. The resident rate of vitreous loss in this study is comparable with other resident-only studies, rates of which vary from $0 \%$ to $10.0 \%$ (Table 6). ${ }^{1-9,11}$

The results of this study are limited by lack of preoperative information on the pre-existing systemic medical conditions and type and maturity of cataracts in the eyes of patients included in the study group. It was therefore not possible to study the association of these 2 factors with the postoperative BCVA outcomes and complications.

Analysis of the postoperative BCVAs for the various types and severities of postoperative complications would also make the interpretation of complication rates more appreciable. Specifically,

Table 5. Comparison of best-corrected visual acuity for cataract surgeries performed by ophthalmology residents.

\begin{tabular}{|c|c|c|c|c|c|}
\hline \multirow[t]{3}{*}{ Study } & \multirow[t]{3}{*}{ Country } & \multicolumn{4}{|c|}{ Best-corrected visual acuity } \\
\hline & & \multicolumn{2}{|c|}{ Month 1} & \multicolumn{2}{|c|}{ Month 3} \\
\hline & & $6 / 12$ or better & $6 / 9$ or better & $6 / 12$ or better & $6 / 9$ or better \\
\hline Quillen and Phipps, ${ }^{5} 2003$ & USA & \multicolumn{4}{|c|}{$89.0 \%$ with $6 / 12$ or better* } \\
\hline Thomas et al, ${ }^{6} 1997$ & India & $94.8 \%$ at 6 weeks & $\begin{array}{l}72.9 \% \text { with } 6 / 6 \text { or } \\
\text { better at } 6 \text { weeks }\end{array}$ & - & - \\
\hline Blomquist and Rugwani, ${ }^{7} 2002^{\dagger}$ & USA & \multicolumn{4}{|c|}{$77.0 \%$ with $6 / 12$ or better at a minimum of 1 month } \\
\hline This study & Singapore & $98.4 \%$ & $85.9 \%$ & $100.0 \%$ & $94.5 \%$ \\
\hline
\end{tabular}

*Follow-up period not available.

${ }^{\dagger}$ Cataract surgeries included phacoemulsification, extracapsular cataract extraction, and intracapsular cataract extraction. 
Table 6. Comparison of posterior capsule rupture rates for cataract surgeries performed by ophthalmology residents.

\begin{tabular}{|c|c|c|c|c|c|c|c|}
\hline \multirow[t]{2}{*}{ Study } & \multirow[t]{2}{*}{ Country } & \multirow[t]{2}{*}{ Review period } & \multirow[t]{2}{*}{ Level of training } & \multirow{2}{*}{$\begin{array}{l}\text { Number of } \\
\text { surgeries }\end{array}$} & \multicolumn{3}{|c|}{ Posterior capsule rupture (\%) } \\
\hline & & & & & Overall rate & $\begin{array}{l}\text { Without } \\
\text { vitreous loss }\end{array}$ & $\begin{array}{l}\text { With } \\
\text { vitreous loss }\end{array}$ \\
\hline Hollander et al, ${ }^{1} 2006^{*}$ & USA & 1983-2002 & Residents $^{\ddagger}$ & 2718 & - & - & 6.7 \\
\hline Khatibi et al, ${ }^{2} 2008^{*}$ & USA & $1996-2005$ & Residents $^{\ddagger}$ & 4501 & - & - & $6.7^{\S}$ \\
\hline Bhagat et al, ${ }^{3} 2007^{\dagger}$ & USA & $2000-2005$ & Third-year residents & 755 & 6.7 & - & 5.4 \\
\hline $\begin{array}{l}\text { Buchan and Cassels- } \\
\text { Brown, }{ }^{4} 2008\end{array}$ & UK & $\begin{array}{l}\text { Dec 2006- } \\
\text { Mar } 2007\end{array}$ & $\begin{array}{l}\text { First-year registrars/ } \\
\text { fourth-year residents }\end{array}$ & 4322 & 2.3 & - & - \\
\hline Quillen and Phipps, ${ }^{5} 2003$ & USA & $1999-2001$ & Third-year residents & 332 & - & - & 4.8 \\
\hline Thomas et al, ${ }^{6} 1997$ & India & - & $\begin{array}{l}\text { Final-year Master of } \\
\text { Surgery residents }\end{array}$ & 70 & - & - & 10.0 \\
\hline $\begin{array}{l}\text { Blomquist and Rugwani, } \\
2002^{\dagger}\end{array}$ & USA & 1997-1999 & Third-year residents & 1400 & - & - & $4.5^{\pi}$ \\
\hline \multirow[t]{3}{*}{ Tayanithi et al, ${ }^{8} 2005$} & Thailand & 1998-1999 & Third-year residents & 404 & - & - & 6.93 \\
\hline & & & Faculty staff & 1358 & - & - & 2.06 \\
\hline & & & $\begin{array}{l}\text { Third-year residents and } \\
\text { faculty staff }\end{array}$ & 1762 & - & - & 3.18 \\
\hline Desai et al, ${ }^{9} 1999^{\dagger}$ & UK & Sep-Dec 1997 & Surgeons at all levels & 18454 & - & - & 4.4 \\
\hline \multirow[t]{2}{*}{ Corey and Olson, ${ }^{11} 1998$} & USA & - & First-year residents & First 50 cases & - & - & 2.6 \\
\hline & & & Final year residents & Last 50 cases & - & - & 0 \\
\hline \multirow[t]{4}{*}{ This study } & Singapore & Jan-Dec 2008 & $\begin{array}{c}\text { Medical officers } \\
\text { (third-year residents) }\end{array}$ & 24 & 0 & 0 & 0 \\
\hline & & & $\begin{array}{l}\text { Registrars (fourth- to } \\
\text { sixth-year residents) }\end{array}$ & 41 & 4.9 & 4.9 & 0 \\
\hline & & & All residents & 65 & 3.1 & 3.1 & 0 \\
\hline & & & All surgeons & 318 & 3.5 & 1.9 & 1.6 \\
\hline
\end{tabular}

${ }^{*}$ Cataract surgeries included phacoemulsification and extracapsular cataract extraction.

${ }^{\dagger}$ Cataract surgeries included phacoemulsification, extracapsular cataract extraction, and intracapsular cataract extraction.

₹Year of training not available.

sIn one of 2 centres.

${ }^{\$ 4.3 \%}$ for phacoemulsificattion and $6.3 \%$ for extracapsular cataract extraction; only 1 patient underwent intracapsular cataract extraction.

it would have been meaningful to compare the difference in the postoperative BCVAs between surgeries complicated by PCR with and without vitreous loss. However, the small numbers in each of these 2 groups are likely to yield results of low statistical significance.

In view of the patient selection method, the number of surgeries performed by residents could not be effectively matched and compared with those performed by consultants despite their clinical relevance and statistical significance.

Phacoemulsification remains a widely accepted method of treatment for cataracts in a predominantly Asian population. In this study, for resident-performed phacoemulsification, the rate of PCR was $3.1 \%$ and the rate of vitreous loss was $0 \%$. These results are comparable with results reported by other centres. Additionally, better postoperative BCVA LogMAR values were found to be associated with a higher level of surgical experience of the attending surgeon and a shorter duration of surgery.

With the ever-increasing number of patients requiring cataract surgery in an ageing population such as in Singapore, continued closely supervised training for ophthalmology residents at a restructured
Asian training hospital will ensure that postoperative complication rates remain low while maintaining postoperative outcomes at safe levels.

\section{References}

1. Hollander DA, Vagefi MR, Seiff SR, Syewart JM. Bacterial endophthalmitis after resident-performed cataract surgery. Am J Ophthalmol. 2006;141:949-51.

2. Khatibi A, Naseri A, Stewart JM. Rate of rhegmatogenous retinal detachment after resident-performed cataract surgery is similar to that of experienced surgeons. Br J Ophthalmol. 2008;92:438.

3. Bhagat N, Nissirios N, Potdevin L, et al. Complications in residentperformed phacoemulsification cataract surgery at New Jersey Medical School. Br J Ophthalmol. 2007;91:1315-7.

4. Buchan JC, Cassels-Brown A. Determinants of cataract surgical opportunities and complication rates in UK higher specialist training. Eye. 2008;22:1425-9.

5. Quillen DA, Phipps SJ. Visual outcomes and incidence of vitreous loss for residents performing phacoemulsification without prior planned extracapsular cataract extraction experience. Am J Ophthalmol. 2003;135:732-3.

6. Thomas R, Naveen S, Jacob A, Braganza A. Visual outcome and complications of residents learning phacoemulsification. Indian $\mathrm{J}$ Ophthalmol. 1997;45:215-9.

7. Blomquist PH, Rugwani RM. Visual outcomes after vitreous loss during cataract surgery performed by residents. J Cataract Refract 
Surg. 2002;28:847-52.

8. Tayanithi P, Pungpapang K, Siramput P. Vitreous loss during phacoemulsification learning curve performed by third-year residents. J Med Assoc Thai. 2005;88 (9 Suppl):S89-93.

9. Desai $P$, Minassian DC, Reidy A. National cataract surgery survey 1997-8: a report of the results of the clinical outcomes. $\mathrm{Br} \mathrm{J}$ Opthalmol. 1999;83:1336-40.

10. Allison RW, Metrikin DC, Fante RG. Incidence of vitreous loss among third-year residents performing phacoemulsification. Ophthalmology. 1992;99:726-30.

11. Corey RP, Olson RJ. Surgical outcomes of cataract extractions performed by residents using phacoemulsification. J Cataract Refract Surg. 1998;24:66-72.

12. Singapore Department of Statistics. Population trends 2008. Available from: http://app.www.sg/data/usermedia/documents/ population2008.pdf Accessed 16 August 2011.

13. Oetting TA. Surgical competency in residents. Curr Opin Ophthalmol. 2009;20:56-60.
14. Binnbaum G, Volpe NJ. Ophthalmology resident surgical competency: a national survey. Ophthalmology. 2006;113:1237-44.

15. Randleman JB, Wolfe JD, Woodward M, Lynn MJ, Cherwek DH, Srivastava SK. The resident surgeon phacoemulsification learning curve. Arch Ophthalmology. 2007;125:1215-9.

16. Randleman JB, Srivastava SK, Aaron MM. Phacoemulsification with topical anaesthesia performed by resident surgeons. J Cataract Refract Surg. 2004;30:149-54.

17. Bell CM, Hatch WW, Cernat G, Urbach DR. Surgeon volumes and selected patient outcomes in cataract surgery: a population-based analysis. Ophthalmology. 2007; 114:405-10.

18. Gauba V, Tsangaris P, Tossounis C, Mitra A, McLean C, Saleh GM. Human reliability analysis of cataract surgery. Arch Ophthalmol. 2008;126:173-7

19. Zaidi FH, Corbett MC, Burton BJ, Bloom PA. Raising the benchmark for the 21st century: the 1000 cataract operations audit and survey: outcomes, consultant-supervised training and sourcing NHS choice. Br J Ophthalmol. 2007;91:731-6. 